\title{
EFFECT OF NEAR-SURFACE MOUNTED BARS ON THE STRUCTURAL BEHAVIOR OF ONE-WAY RC SLAB
}

\author{
Hayder H. Kamonna ${ }^{1}$ and Douaa J. Abd Al-Sada ${ }^{2}$ \\ ${ }^{1}$ Prof. Dr., Civil Engineering Department, Kufa University, Iraq. Email: \\ hayder.kammona@uokufa.edu.iq
}

2 M. Sc. Student, Civil Engineering Department, Kufa University, Iraq. Email: eng140246@student.uokufa.edu.iq

HTTP://DX.DOI.ORG/10.30572/2018/KJE/120302

\begin{abstract}
The present research paper deals with the finite element modelling of continuous one-way reinforced concrete (RC) slabs strengthened by near surface mounted (NSM) bars under static loads. Seven specimens that consisted of one reference slab without strengthening and six strengthened slabs were used, with $2400 \mathrm{~mm}$ total length, $500 \mathrm{~mm}$ width and $100 \mathrm{~mm}$ thickness. The average compressive concrete strength at 28 days' age was about $31 \mathrm{MPa}$ was used. Slabs were simulated with finite element computer program. The results of the control and strengthened slabs were compared with the experimental results. It is observed that the results of the strengthened slabs are in close agreement with the experimental results with a maximum difference in the ultimate load of about $6.64 \%$.
\end{abstract}

KEYWORDS: Near-surface mounted, one way-slabs, Load-deflection curves, Crack-pattern and Finite element method. 


\section{INTRODUCTION}

In Europe, the use of near surface mounted (NSM) bar technique was advanced for strengthening of reinforced concrete (RC) structures in the early 1950s. In 1948, a RC bridge deck in Sweden wanted to be upgraded in its hogging zone due to an excessive settlement of the steel cage through building. This was done by adding steel reinforcement bars into concrete grooves and by filling them with cement mortar (Parretti and Nanni, 2004). Steel corrosion in $\mathrm{RC}$ structures and elements is a main problem in the United States and around the world, costing billions of dollars in repairs and damages that are needed. It is also very useful to use externally bonded reinforcement for FRP and NSM in order to stabilize and repair but also to avoid further corrosion in concrete structures (Augustine 2013). Using NSM reinforcement can raise the flexural capacity, stiffness and reduces the crack width more than using externally bonded (EB) reinforcement. Experimentally and numerically study on repairing and strengthening of selfcompacted concrete slabs was presented by Ashteyat et al, 2019. The effectiveness of straight and inclined NSM carbon-fiber-reinforced polymers CFRP on the strengthening and repairing of self-compacted concrete slabs. It was found that the ultimate strength of one-way slabs increased by $45 \%-163 \%$ when the strengthened by either inclined and straight NSM-CFRP strips. In addition, repairing of one-way slabs resulted in a recovered the ultimate strength to about $223 \%$ of the control slabs ultimate strength, with a considerable enhancement in stiffness that reached to 296\%. Abdallah et al. (2020) used NSM carbon and fiber-reinforced polymer (FRP) rods to strengthen the continuous reinforced RC beams. Length, type and ratio of FRP rods in addition to the filling material were the main tested parameters. Test results showed that all the capacity of al strengthened specimens with NSM-FRP increased compared to the control beam. In addition, the failure mode was changed from pull out of the FRP-rods to premature peeling of concrete cover when the rods are terminated before the zero moment point. Most researchers have adopted carbon fiber reinforced polymer (CFRP) as strengthening materials due to its high strength to weight ratio. But there are very limited researches dealt with using steel bars as strengthening materials such as strengthening of corbels (Shakir and Kamonna 2018) shear strengthening of beams (Thamrin et al. 2019), torsional strengthening of beams (Askandar and Mahmood 2020) flexural strengthen of continuous beam (Abdzaid and Kamonna 2019) and deep beams (Kamonna and Al-Issawi 2018, Al-Issawi and Kamonna 2020). There is very limited knowledge of adopting the NSM method by steel bars for strengthening of continuous one- way RC slabs, although it is availability in addition to it is ability of accounting of redistribution load beyond formation of plastic hinge which may occur 
in continuous members. This phenomenon could not be account to in case of using CFRP martial due it is brittle nature.

\section{EXPERMENTAL TEST}

Six RC one-way continuous slabs that experimentally were numerically analyzed. These slabs consist of one unstrengthened slab (CS) as a control specimen and five strengthened slabs. Four of the strengthened slabs were strengthened by \#10 steel bars that have different lengths and quantities as shown in Table 1. Carbon fiber rods of $10 \mathrm{~mm}$ in diameter that having tensile strength and modulus of elasticity of $2172 \mathrm{MPa}$ and $124 \mathrm{GPa}$ was adopted to strengthen one of the slab specimens. The last specimen was strengthened by 6 \#10 steel bars. Epoxy-paste known as Sikadur ${ }^{\circledR} 330$ and produced by Sika was used to bond the strengthening bars. All slabs have $100 \mathrm{~mm}$ thick, $500 \mathrm{~mm}$ width, and $2400 \mathrm{~mm}$ total length. Tests were done under two-point loads centered at two spans that having clear lengths of $1100 \mathrm{~mm}$. The compressive strength, splitting tensile strength and modulus of rupture of concrete were equal to $31 \mathrm{MPa}, 2 \mathrm{MPa}$ and 4.57 $\mathrm{MPa}$ respectively. Two meshes of steel reinforcement were used to reinforce slab specimens located at their top and bottom faces as shown in Fig 1. Each mesh consisted of \#8 at $200 \mathrm{~mm}$ c,c as main reinforcement, and \#8 at $380 \mathrm{~mm} \mathrm{c,c}$ as secondary reinforcement. Table 2 lists properties of reinforcing and strengthening steel bars.

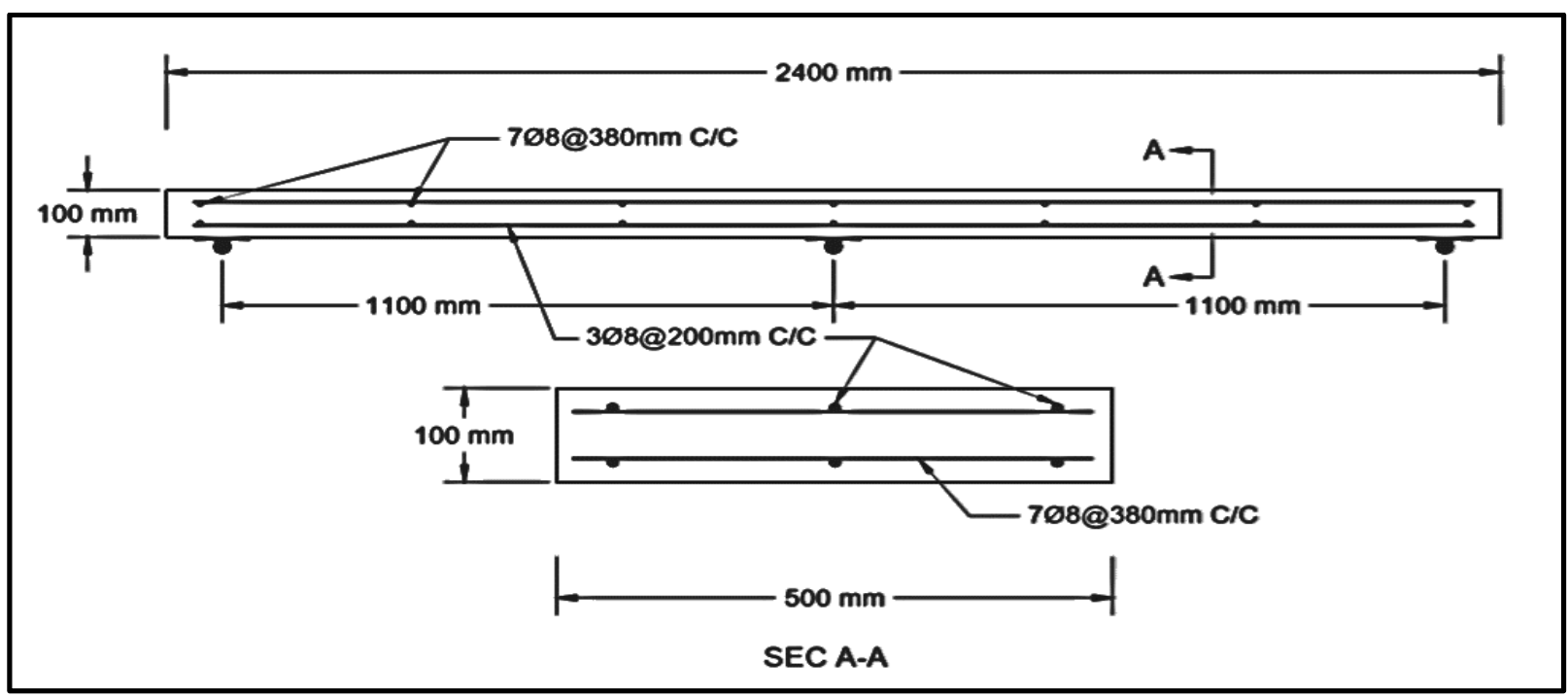

Fig. 1. Dimensions and reinforcement details of a typical tested slab. 
Table 1. Designations and strengthening details of tested slabs.

\begin{tabular}{|c|c|c|c|c|c|}
\hline Specimen name & $\begin{array}{l}\text { Number of } \\
\text { strengthene } \\
\text { d bars }\end{array}$ & $\begin{array}{c}\text { Material type } \\
\text { of strengthened } \\
\text { bars }\end{array}$ & $\begin{array}{l}\text { NSM Length } \\
\text { in Negative } \\
\text { moment Zone }\end{array}$ & $\begin{array}{l}\text { NSM Length } \\
\text { in positive } \\
\text { moment Zone }\end{array}$ & $\begin{array}{c}\text { End } \\
\text { anchor }\end{array}$ \\
\hline CS (control slab) & - & - & - & - & - \\
\hline SS94.9 & 4 & Steel & $0.9 \mathrm{~L}^{*}$ & $0.9 \mathrm{~L}$ & \\
\hline SS94.6 & 4 & Steel & $0.6 \mathrm{~L}$ & $0.9 \mathrm{~L}$ & \\
\hline SS64.9 & 4 & Steel & $0.9 \mathrm{~L}$ & $0.6 \mathrm{~L}$ & \\
\hline SC94.9 & 4 & Carbon & $0.9 \mathrm{~L}$ & $0.9 \mathrm{~L}$ & --------- \\
\hline SS96.9 & 6 & Steel & $0.9 \mathrm{~L}$ & $0.9 \mathrm{~L}$ & --------- \\
\hline
\end{tabular}

Table 2. Properties of reinforcing and strengthening steel bars.

\begin{tabular}{ccc}
\hline Nominal bar size $(\mathbf{m m})$ & Yield Strength (MPa) & Ultimate Strength ( MPa) \\
\hline 8 & 510 & 632 \\
10 & 460 & 687 \\
\hline
\end{tabular}

\section{FINITE ELEMENT MODELING}

In the FEM, the structure was divided into finite elements connected together by their nodes. ANSYS software is the comment tool that used for this purpose. To achieve analysis process by ANSYS, it is required to define (element type, section and real constant for each element in addition to the applying loads, and boundary conditions).

\subsection{Modeling.}

Modeling of RC slab is done using:

SOLID65 element is used for representing the concrete because of its ability in taking account of crushing and cracking of concrete that occurred when compression and tension stresses exceeded concrete compression and tension strengths. Besides to that, it has the feature of adding reinforcement material to the concrete element as shown in Fig 2.

LINK180 element which is a uniaxial 3D bar-element is used for simulating steel reinforcement and NSM strengthening bars as shown in Fig 3.

SOLID185 element is used for representing the bearing plates above the supports and under loads to avoid local failure of concrete as shown in Fig 4. 


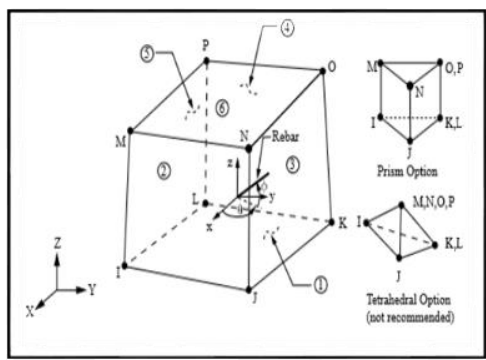

Fig. 2. SOLID 65 Element.

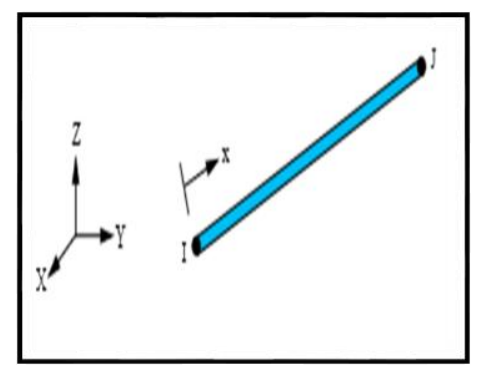

Fig. 3. LINK180 Element.

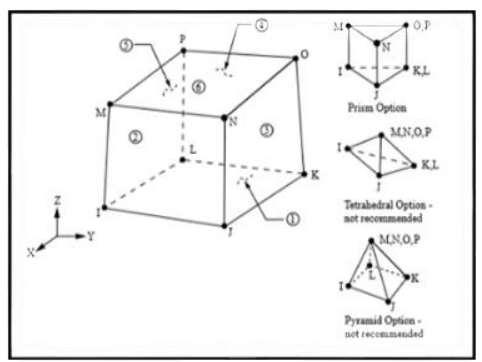

Fig. 4. SOLID185 Element.

Element attributes which adopted in the present works are shown in Table 3. A quarter of the entire model is shown in Fig. 5. The main and transverse steel reinforcement modeling are shown in Fig. 6. Modeling of NSM steel reinforcement is shown in Fig. 7.

Table 3. Element attributes.

\begin{tabular}{ccccc}
\hline Model & $\begin{array}{c}\text { Element } \\
\text { Type }\end{array}$ & $\begin{array}{c}\text { Real } \\
\text { Constant }\end{array}$ & Sections Link & $\begin{array}{c}\text { Material } \\
\text { Number }\end{array}$ \\
\hline $\begin{array}{c}\text { Concrete } \\
\text { Steel Plate }\end{array}$ & SOLID65 & 1 & $\ldots \ldots$. & 1 \\
\#8 steel and NSM bar & LINK185 & 1 & $\ldots \ldots$ & 2 \\
\#10 NSM bar & LINK180 & $\ldots \ldots .$. & 8 & 8 \\
$\# 12$ CFRP NSM bar & LINK180 & $\ldots \ldots$. & 10 & 10 \\
$\# 14$ (12) NSM bar & LINK180 & $\ldots \ldots$. & 12 & 12 \\
\hline
\end{tabular}

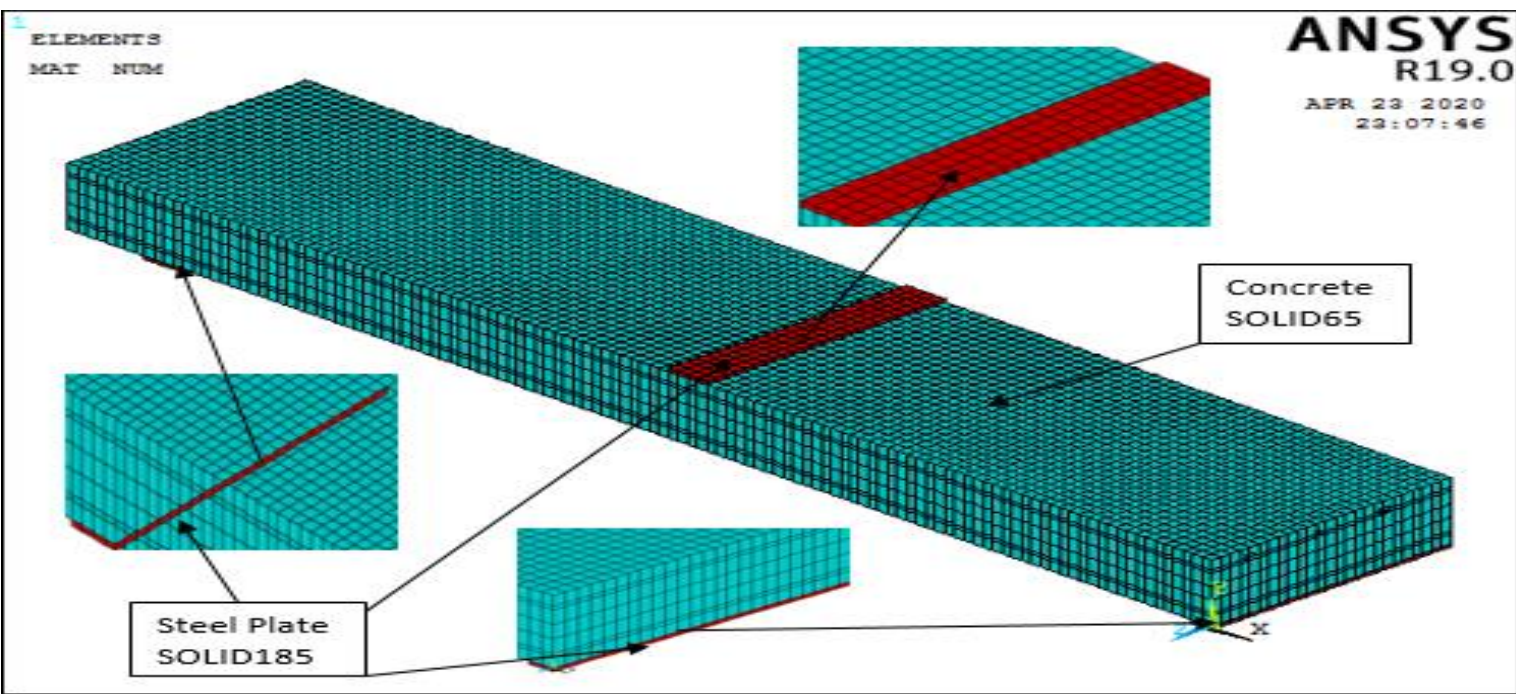

Fig. 5. Types of elements used in FE modelling. 


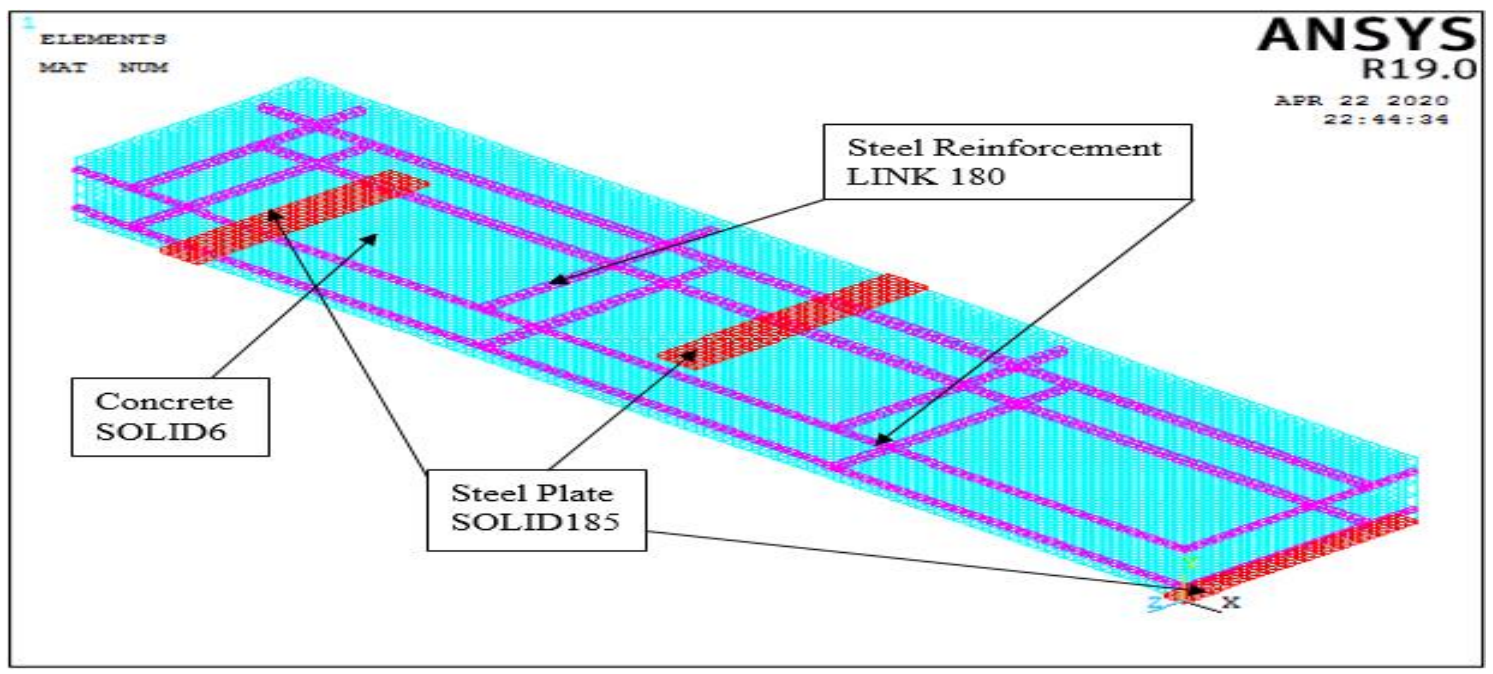

Fig. 6. Main and transverse steel reinforcement modelling.

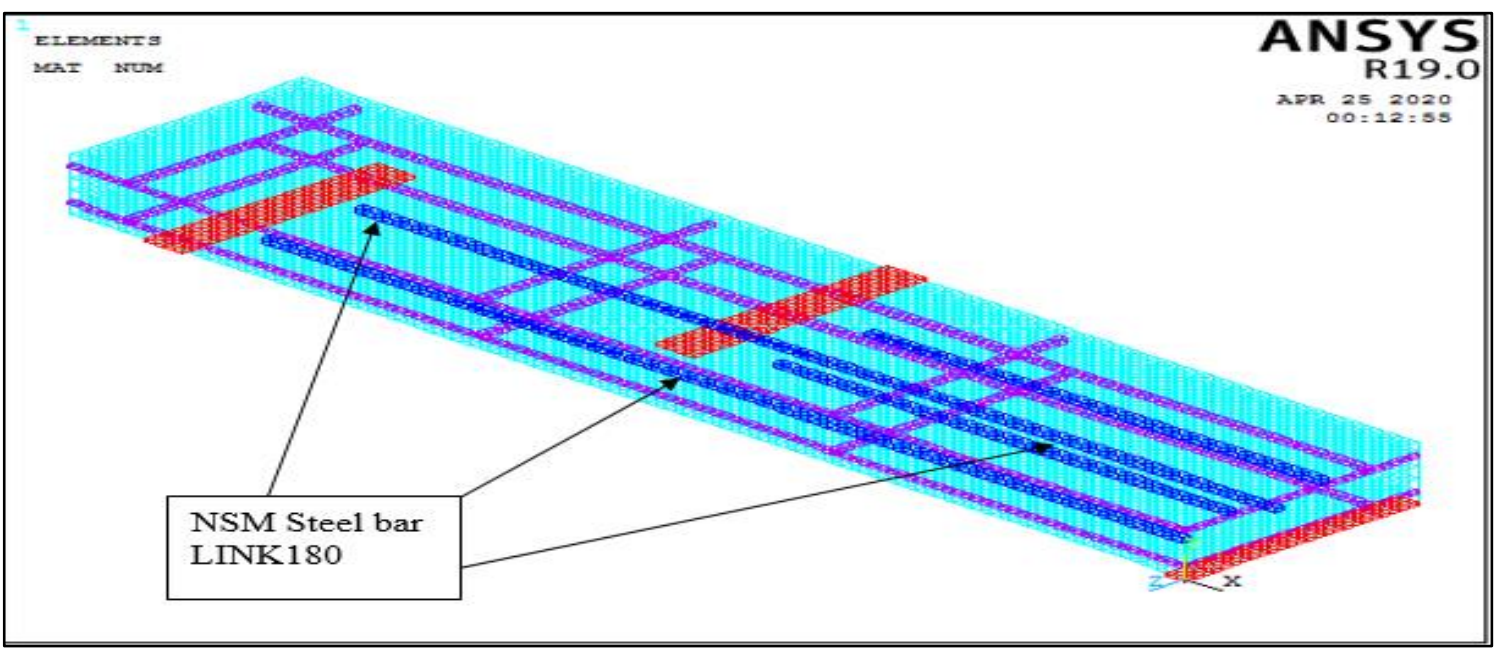

Fig. 7. Modelling of NSM steel reinforcement.

\subsection{Material Properties}

In this analysis, three types of material properties were used. Solid 65 element was the first material (material number 1), this element requires the definition of linear isotropic, concrete parameters and multilinear properties show Table 4. The material number 2 was link 180. The element requires defining linear isotropic and bilinear properties show Table 5. The material number 3 for solid 185 was the last material and requires only linear isotropic, show Table 6. The stress-strain constitutive relationships shown in Fig. 8 were used to simulate concrete behavior under compression and tension. A bilinear and linear stress-strain relationships are used to represent steel and carbon bars, as shown in Fig. 9. For simplicity, epoxy was modeled as concrete with full bond assumption between concrete and epoxy in one side and epoxy and steel on another side. So, Solid65 element is used to represent the epoxy. 

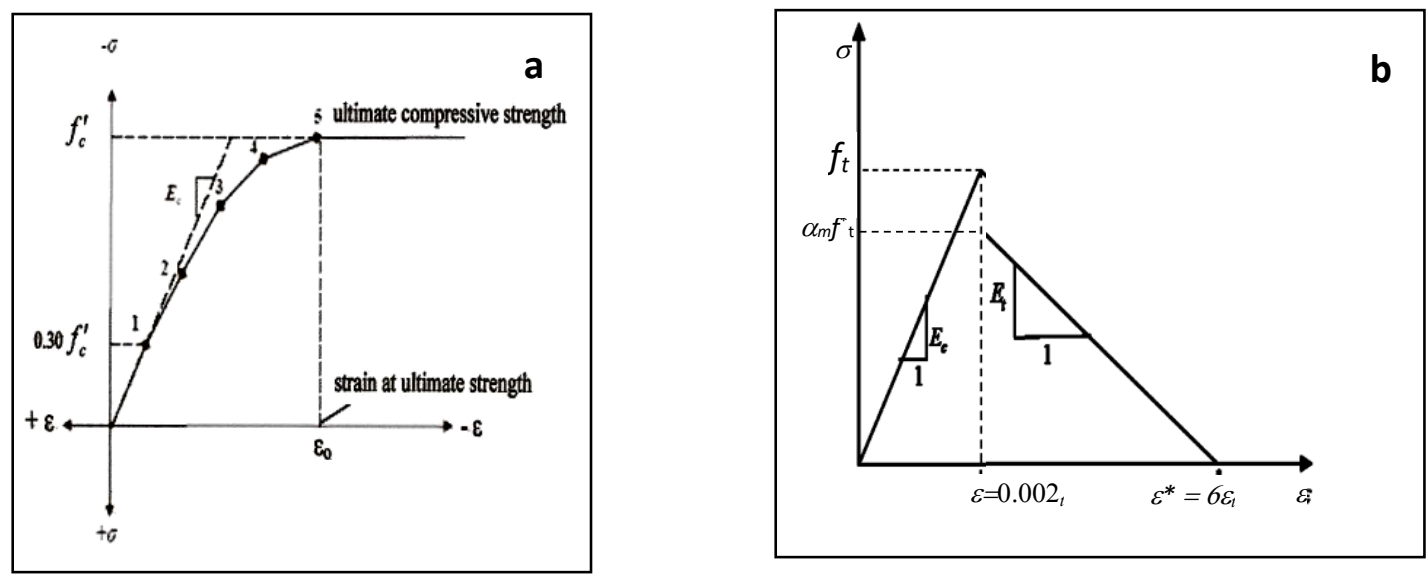

Fig. 8. The assumed stress-strain relationship of Concrete a: in compression (Willam, and Warnke, 1974); b. in tension (ANSYS, 2016).

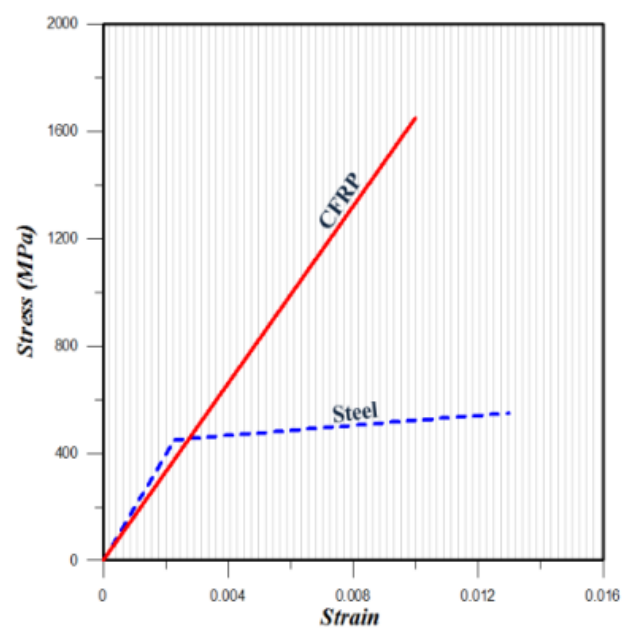

Fig. 9. The assumed stress-strain relationship for steel and CFRP bars.

Table 4. Material Properties for (SOLID 65).

\begin{tabular}{ccc}
\hline \multicolumn{3}{c}{ Linear. Isotropic } \\
\hline $\begin{array}{c}\text { Modulus of Elasticity (Ec), MPa } \\
\text { Poison's Ratio }\end{array}$ PRXY & 0.2 \\
\hline \multicolumn{1}{c}{ Concrete. Parameters } \\
\hline Transfer Coefficient of Open Shear Cracks & $0.01-0.04$ \\
Transfer Coefficient of Closed Shear Cracks & $0.03-0.1$ \\
Concrete Cracking Stress & 2 \\
Concrete Crushing Stress & 31 \\
Tensile Crack Factor & 0.68
\end{tabular}


Table 5. Material Properties for (LINK 180).

\begin{tabular}{cc}
\hline \multicolumn{2}{c}{ Linear Isotropic } \\
\hline Modulus of Elasticity, MPa & 200000 \\
Poison's Ratio & 0.3 \\
\hline Bilinear Isotropic \\
\hline Yield Stress(fy), MPa & 510 \\
Tangent Modulus, MPa & 2000 \\
\hline
\end{tabular}

Table 6. Material Properties for (SOLID185).

\begin{tabular}{cc}
\hline \multicolumn{2}{c}{ Linear Isotropic } \\
\hline Modulus of Elasticity, MPa & 200000 \\
\hline Poison's Ratio & 0.3 \\
\hline
\end{tabular}

\subsection{Loads and Boundary Conditions}

The simulation of a one-way RC slab was achieved for just a quarter of a continuous concrete slab using two planes of symmetry. Therefore, displacements perpendicular to planes of symmetry in the direction were set as zero $(\mathrm{Uz}=\mathrm{Ux}=0)$. In addition, the displacements in all supports were modeled in such way they will be work as a roller $(\mathrm{Uy}=0)$ as illustrated in Fig 10. Steel plates having dimensions $(250 \mathrm{~mm} \times 40 \mathrm{~mm} \times 5 \mathrm{~mm})$ were added to avoid stress concentration in concrete which may result in numerical problems before occurrence of true slab failure. The external load applied (P) was expressed by the nodal forces on the centerline of the steel plate on the top of the slab. The equivalent forces were equal $(\mathrm{P} / 400)$ for the exterior nodes and (P/200) for the interior nodes where $\mathrm{P}$ is the actual applied force as shown in Fig. 11.

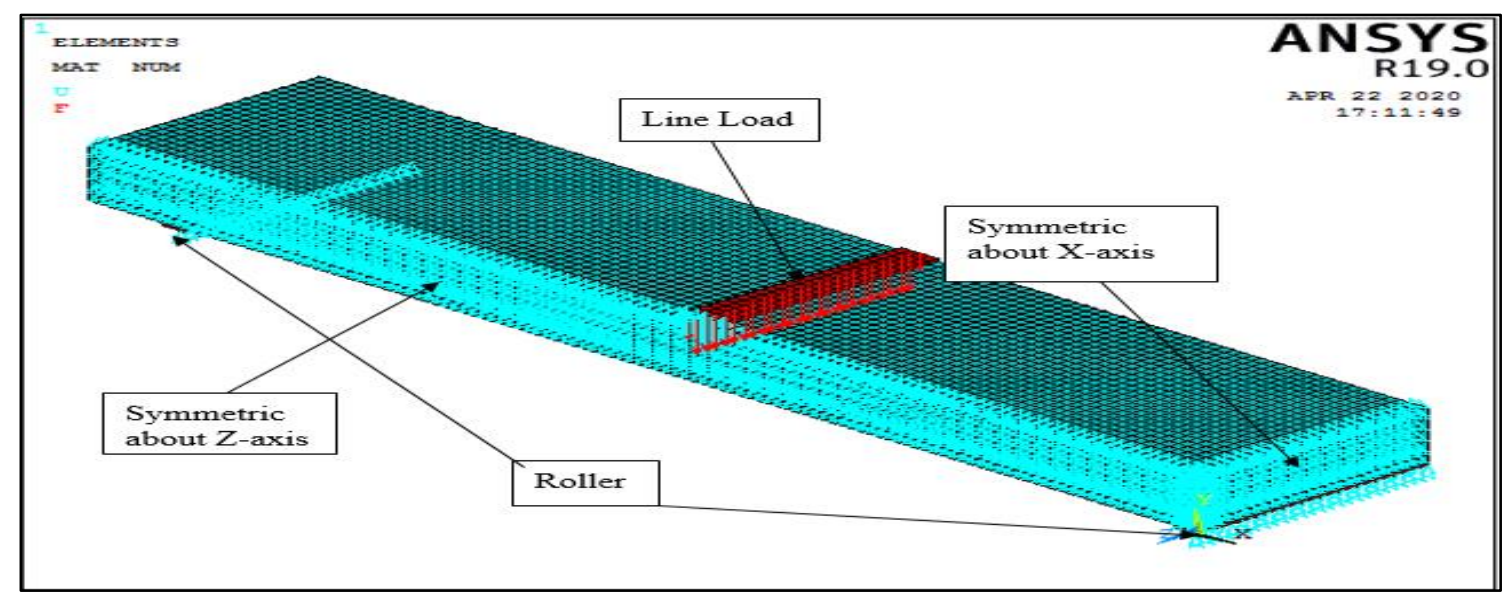

Fig. 10. Boundary conditions for the quarter RC slab. 


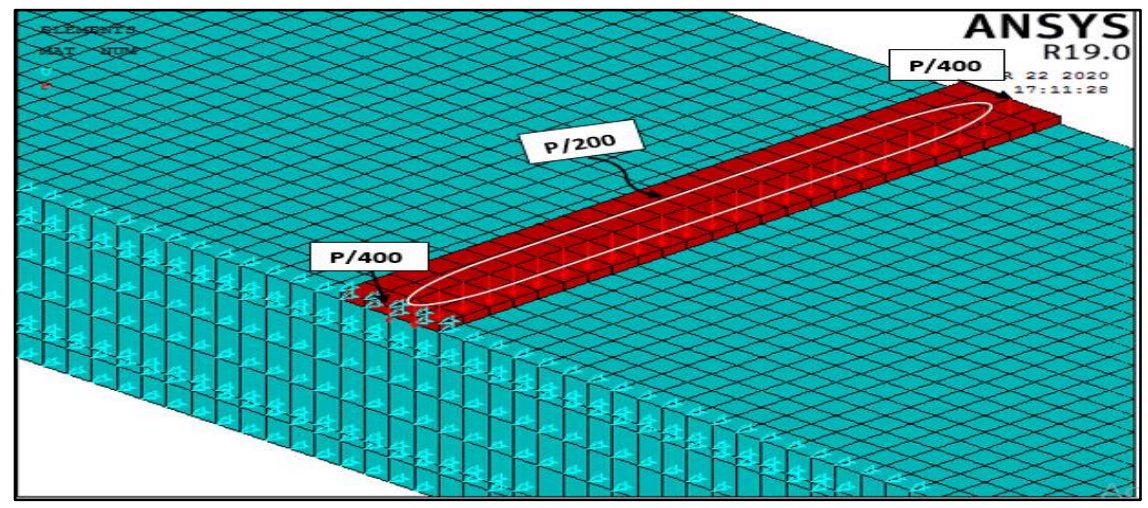

Fig. 11. Applied line load distribution on all nodes.

\section{RESULTS AND DISCUSSION}

\subsection{Load-deflection curves.}

Fig.s 12-17 show that the load-mid span deflection curves that obtained from the present analysis. Generally, the analysis results can be considered agreed well with the experimental results. Some stiffer solution can be noticed in the CB, SS94.9 and SS94.6 specimens. This may be attributed the assumptions of homogeneous material (no hero-cracks concrete) which may reduce concrete stiffness, in addition to the assumptions of full bond between epoxy and concrete and between strengthening bars and epoxy. Beside to those, failure criteria of the concrete depended on uniaxial test whereas concrete elements in the slab body were exposed to either biaxial or triaxil stresses. In the other side, the solution improves more in the cases contained higher strengthening ratio due to more dependence on steel which considered as a more homogeneous material. Modeling of such materials will have more reasonable assumptions.

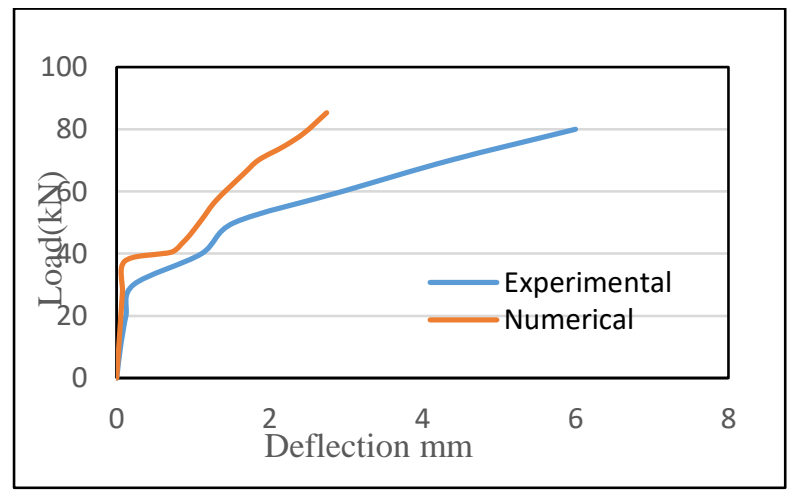

Fig. 12. Comparison between the numerical and experimental load-deflections curves CS.

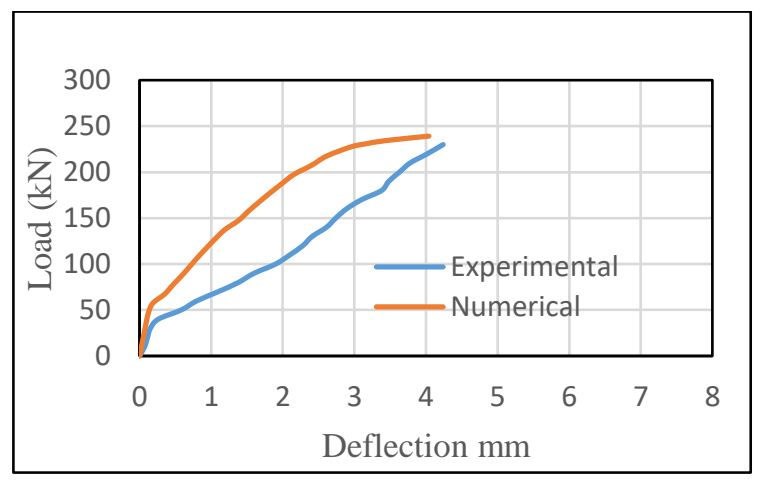

Fig. 13. Comparison between the numerical and experimental load-deflections curves SS94.9. 


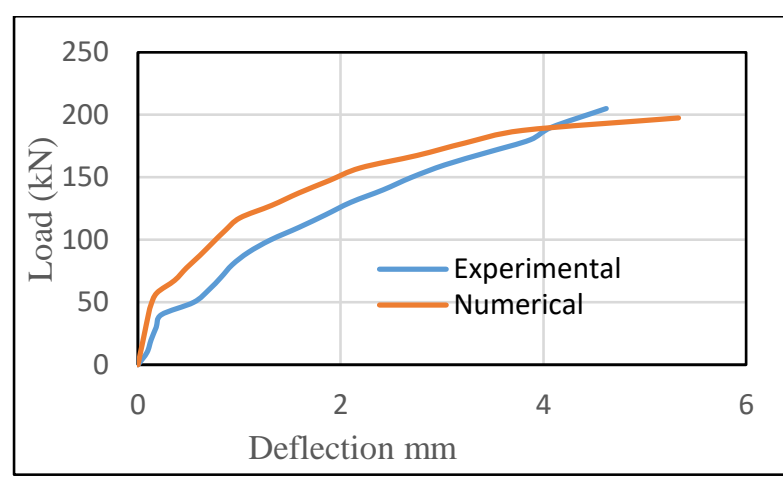

Fig. 14. Comparison between the numerical and experimental load-deflections curves SS94.6.

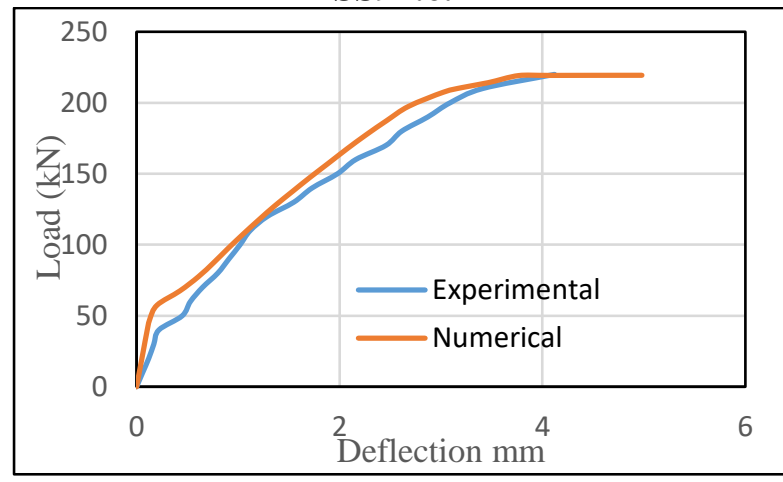

Fig. 16. Comparison between the numerical and experimental load-deflections curves SC94.9.

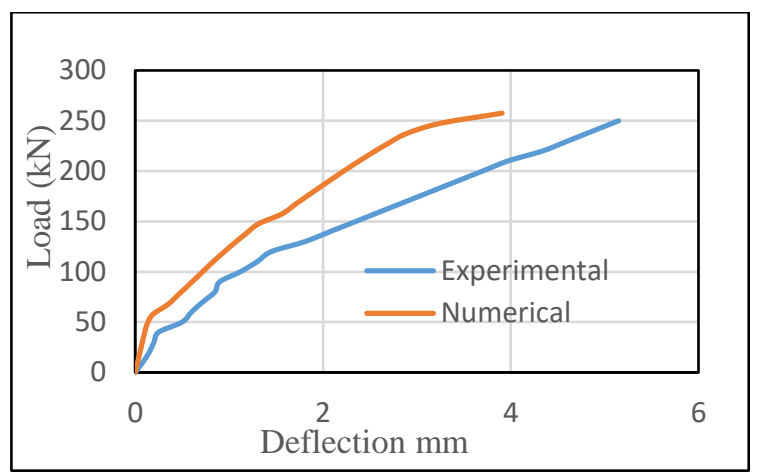

Fig. 15.Comparison between the numerical and experimental load-deflections curves SS64.9.

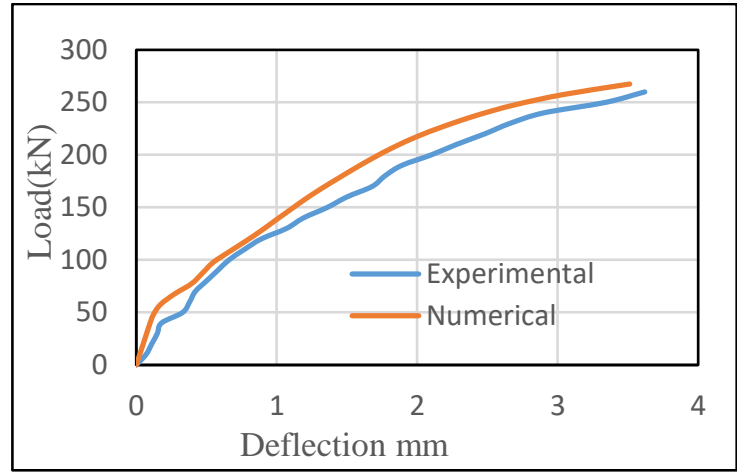

Fig. 17.Comparison between the numerical and experimental load-deflections curves SS96.9.

\subsection{Crack pattern.}

Figs. 18-23 illustrate that the crack patterns of the experimental and numerical results of the continuous RC slab. Slab cracking patterns were obtained by the ANSYS Crack / Crushing plot option. Numerically, failure of the analyzed slab is decided by when resulting displacements or plastic strains in one or more nodes become larger than specified values or the solution could not be converged by although a high number of iterations is applied. The specified values were chosen as those default values suggested in the ANSYS program. From all figures, it can be noted that the first crack generates at the bottom face (sagging region) from both mid-span of all specimen's slab. The control specimen and the SS94.6 specimen slab (which strengthened by NSM steel bars having embedded length of $0.6 \mathrm{~L}$ in the positive moment region) failed by flexure when they reached the ultimate load. The other specimens (SS94.9, SS64.9, SC94.9 and SS96.9) failed by peeling of concrete cover. It is noted that the numerical results are good agreed with the crack pattern obtained from experimental work. 


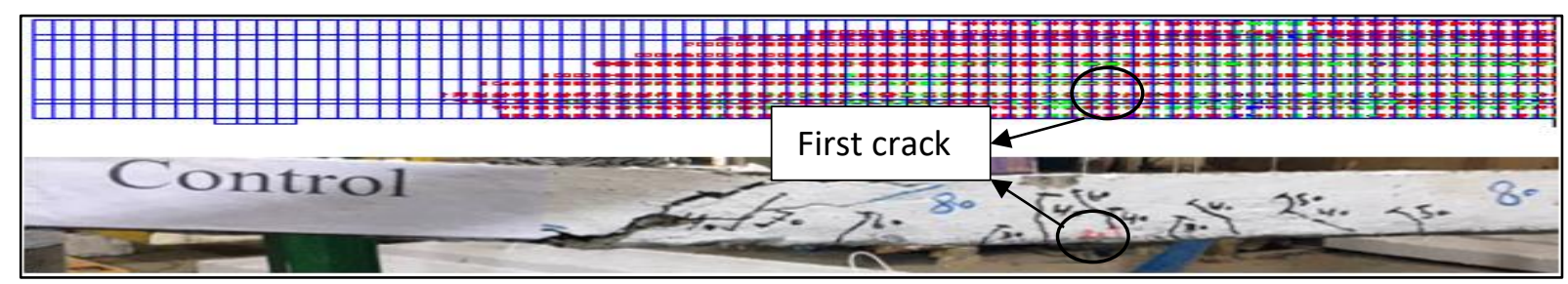

Fig. 18. Comparison between the experimental and numerical crack patterns of CS.

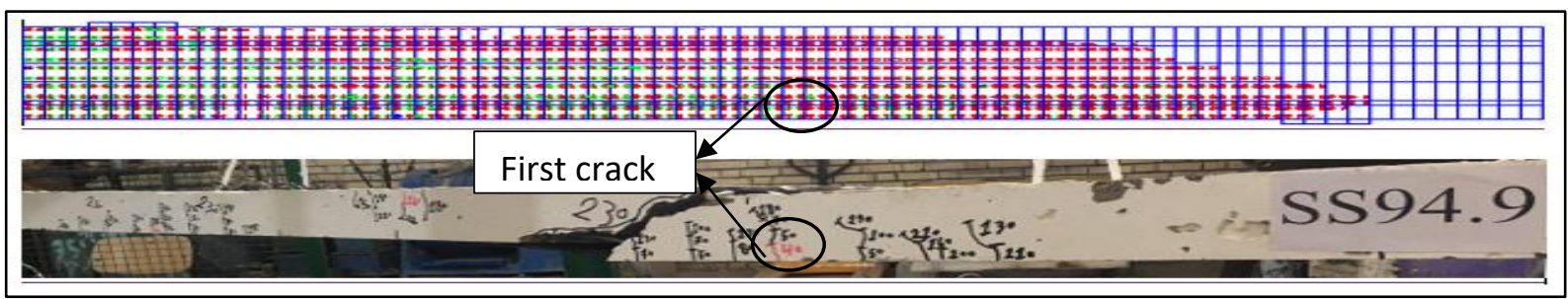

Fig. 19. Comparison between the experimental and numerical crack patterns of SS94.9.

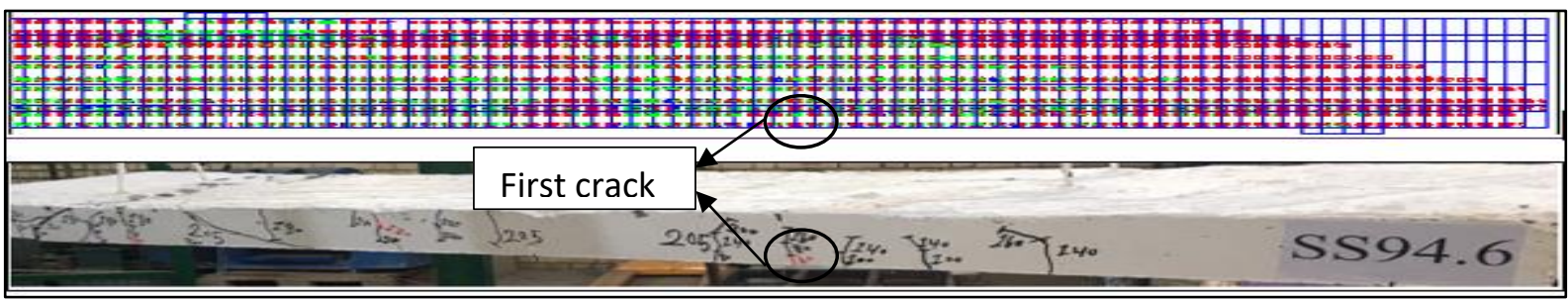

Fig. 20. Comparison between the experimental and numerical crack patterns of SS94.6.

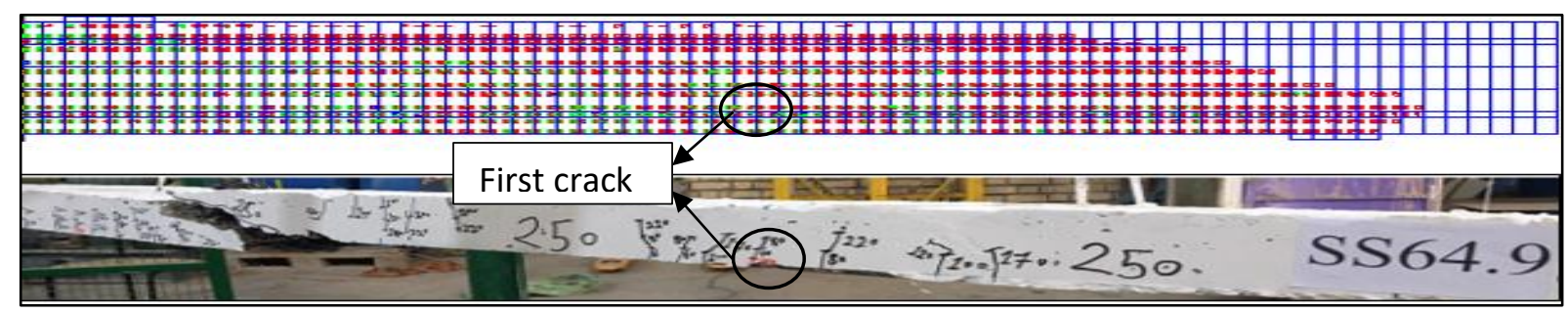

Fig. 21. Comparison between the experimental and numerical crack patterns of SS64.9.

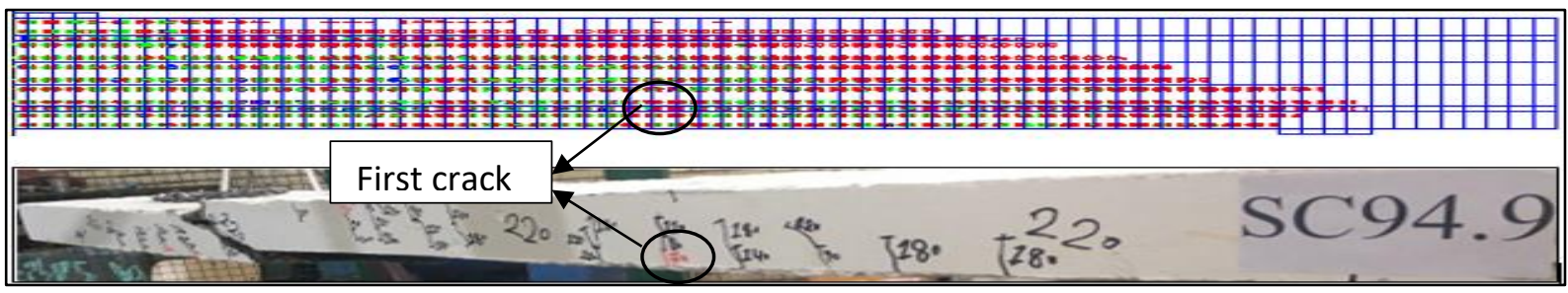

Fig. 22. Comparison between the experimental and numerical crack patterns of SC94.9.

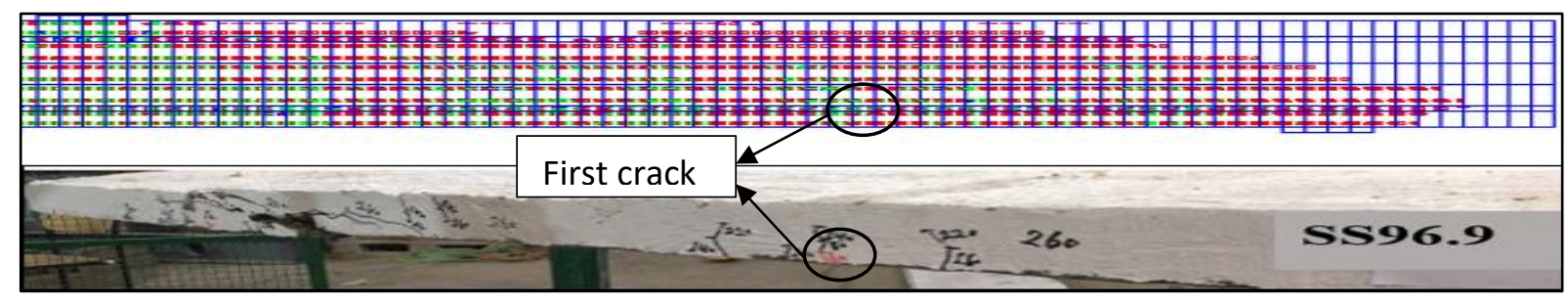

Fig. 23. Comparison between the experimental and numerical crack patterns of SS96.9. 


\subsection{Ultimate load}

It is apparent that the numerical ultimate loads from the FE analysis accord well with the subtending values of the ultimate experimental tests as appeared in Table 7. The maximum variance in the ultimate load was $6.64 \%$ for the tested and analyzed slabs that strengthened by steel bars.

Summarizing of the difference between the ultimate loads and maximum deflection obtained experimentally and numerically depends on the embedded length of NSM bars that put in the sagging and hogging zones (0.9 or 0.6$) \mathrm{L}$, spacing of NSM bars $(100 \mathrm{~mm}$ or $70 \mathrm{~mm}$ ) as well as the material type of NSM bars (CFRP or steel). Results revealed that the ultimate load of one way slab increased by (131-214) \% when the strengthened by NSM-technique. Increasing strengthening quantity by $50 \%$ resulted in an increasing ultimate load by about $12 \%$. Also, using CFRP bars instead of steel bars as strengthening material resulting in a decrease in the ultimate load by about $8 \%$. This may be due to that the CFRP bar is a brittle material that could not help with the formation of plastic hinges. Therefore, in statically indeterminate structure adopting steel bars as strengthening material is a better choice than CFRP bars due to their high ductility. It can be also seen that increasing the embedded bars in the positive moment region gave greater ultimate load than the case in which higher embedded length is used in the negative moment region.

Table 7. Comparison of Experimental and Numerical Final Load that adopted in the present work.

\begin{tabular}{cccccc}
\hline Specimen & $\begin{array}{c}\text { Num. Pu } \\
\text { KN }\end{array}$ & $\begin{array}{c}\text { Exp. Pu } \\
\text { KN }\end{array}$ & $\begin{array}{c}\text { Num. / } \\
\text { Exp. }\end{array}$ & $\begin{array}{c}\text { Difference between } \\
\text { Num. and Exp. }\end{array}$ & $\begin{array}{c}\text { Num. / } \\
\text { Exp. (\%) }\end{array}$ \\
\hline CS & 85.311 & 80 & 1.066 & 0.066 & 6.64 \\
SS94.9 & 239.17 & 230 & 1.039 & 0.039 & 3.99 \\
SS94.6 & 197.5 & 205 & 0.963 & 0.037 & 3.66 \\
SS64.9 & 257.5 & 250 & 1.03 & 0.03 & 3 \\
SC94.9 & 219.37 & 220 & 0.997 & 0.003 & 0.29 \\
SS96.9 & 267.5 & 260 & 1.028 & 0.028 & 2.88 \\
\hline
\end{tabular}

\section{PARAMETRIC STUDY}

To extend of the knowledge on the behavior of one-way RC continues slabs strengthened by NSM bars, some parameters that may effect on the behavior of such member are presented in this section. 


\subsection{Concrete strength.}

In the experimental test, concrete with $31 \mathrm{MPa}$ compressive strength was used. The parametric study included four compressive strengths, one less than $31 \mathrm{MPa}$ which is $20 \mathrm{MPa}$ and the other more than $31 \mathrm{MPa}$ that assumed as 40, 50 and $60 \mathrm{MPa}$. This new material quality will be implemented in SS94.9 specimen slab.

It can be seen from Fig. 24 that changing the compressive strength from (40, 50 and $60 \mathrm{MPa})$, respectively led to increasing the ultimate load by $(5.22 \%, 26.13 \%$ and $57.87 \%)$, respectively compared with the specimen with $31 \mathrm{MPa}$. In the same context, decrease the compressive strength to $20 \mathrm{MPa}$ led to a reduction in the ultimate load by $9.06 \%$ compared with the SS94.9 specimen slab. The obtained relationship is nonlinear, where it is found that the higher enhancement in the ultimate load when adopting higher compressive strength. This may be due to, in addition to the increased section capacity resulted in adopting high compressive strength, decreasing the height of Whitney's block which inversely proportional with the compressive strength without changing its area which leading to increasing the lever arm of the internal couple. Whereas, Whitney's block is a rectangular block proposed by Whitney and checked by Mattock et. al. It is used to approximate the parabolic behavior of the stress-strain behavior of concrete in compression. The width of Whitney's block equals to $0.85 \mathrm{f} \mathrm{f}^{\mathrm{c}}$ and its depth is $\square 1 \mathrm{c}$ where $f^{~} \mathrm{c}$ is concrete compressive strength, $\square 1$ is a factor depends on concrete compressive strength and $\mathrm{c}$ is the depth of neutral axis measured from the extreme of compression face (Hassoun and Al-Manaseer, 2015).

By observing Fig. 25 which shows the effect of changing the concrete compressive strength on the load deflection curves, linear behavior can be seen in the first stage of loading which terminated with initiating of the first cracks that first crack initiated at load values of $47.5 \mathrm{kN}$, $57.5 \mathrm{kN}, 67.5 \mathrm{kN}, 77.5 \mathrm{kN}$, and $87.5 \mathrm{kN}$, for slabs with concrete strength of $20 \mathrm{MPa}, 31 \mathrm{MPa}$, $40 \mathrm{MPa}, 50 \mathrm{MPa}, 60 \mathrm{MPa}$ respectively. Then, the trend of the curve becomes nonlinear with a considerable reduction in the stiffness of the slab which can be noticed by the significant reduction in the slope of the load-deflection curve in the second stage of loading. The second stages are terminated at load values of about $207.5 \mathrm{kN}, 217.5 \mathrm{kN}, 246.67 \mathrm{kN}, 298.33 \mathrm{kN}$ and $267.5 \mathrm{kN}$ for slabs with concrete strength of $20 \mathrm{MPa}, 31 \mathrm{MPa}, 40 \mathrm{MPa}, 50 \mathrm{MPa}, 60 \mathrm{MPa}$. In the last stage of loading, the slope of the curve returns to be reduced. It can be also seen clearly that changing the compressive strength led to increase stiffness and flexural strength. These effects are more pronounced beyond cracking load. 


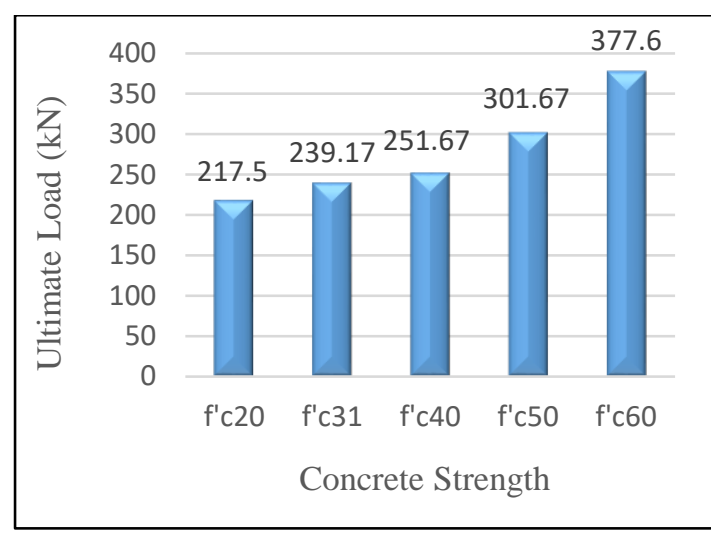

Fig. 24. Influence of Ultimate Load of Concrete Strength.

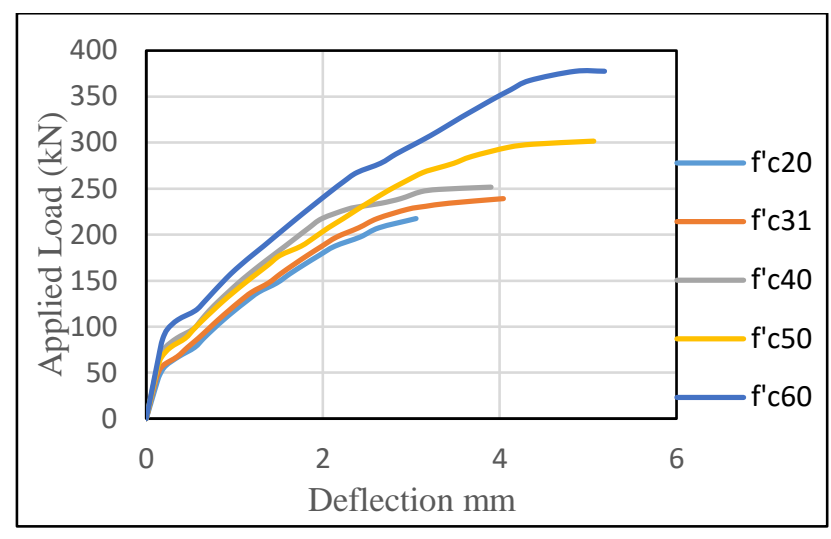

Fig. 25. Load-deflection curves of changing f'c.

\subsection{Location of NSM bars.}

In this section, effect of changing the location NSM bars i.e. (but them in the negative moment region only, positive moment region only or both regions) is investigated. Two values of NSM bars spacing are adopted which are $70 \mathrm{~mm}$ and $100 \mathrm{~mm}$.

\subsubsection{Effect Location of NSM when adopting $70 \mathrm{~mm}$ NSM bars spacing}

In the first specimen only the negative moment zone is strengthened. The results showed increasing in the ultimate load of about $135.5 \%$ compared with the CS, whereas only the positive moment zone is strengthened in the second specimen. The ultimate load was increased by $108 \%$ relative to CS as shown in Fig. 26. When using the strengthening bars just in the negative moment zone led to increase in the ultimate load about $13.2 \%$ relative to the strengthening case when using strengthening bars in only the positive moment zone.

Fig. 27 shows the effect of changing of NSM location on load-deflection curves. In the first stage of loading linear behavior can be seen which terminated with initiating the first crack. Then, the relationship becomes nonlinear. This may have considered as the same trend followed in the previous section. The plastic hinges occurred approximately at the load $200 \mathrm{KN}$ when using the strengthening bars just in the negative moment zone and after that, the slab failed gradually. It is also noticed that more stiffness is obtained when put the NSM at both positive and negative moment zone, while less stiffness when the NSM put only in the negative moment zone. 


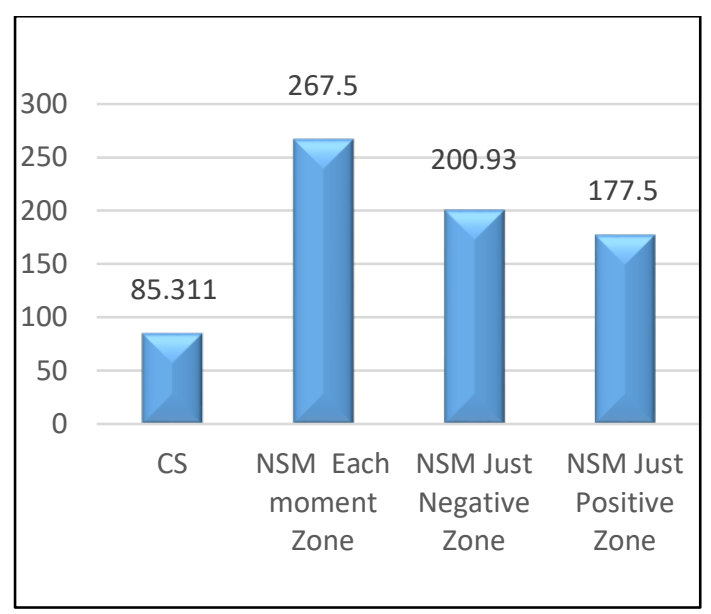

Fig. 26. Influence of NSM location spaced at $70 \mathrm{~mm}$ on ultimate load.

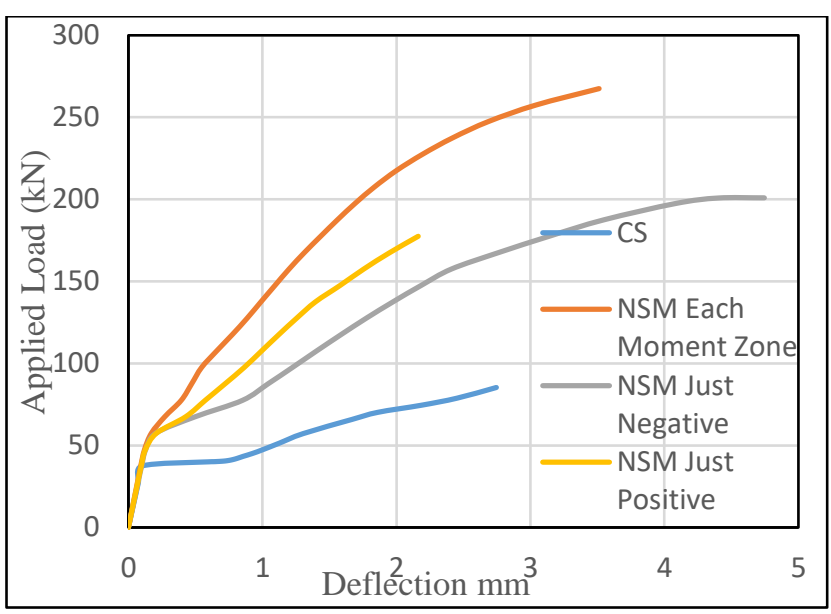

Fig. 27. Load-deflection curves of both moment zones, just negative moment zone and positive moment.

\subsubsection{Effect of NSM Location when adopting $100 \mathrm{~mm}$ NSM bars spacing}

The first specimen is strengthened only in the negative moment zone. The results showed increasing of about $108.47 \%$ in ultimate load compared with the CS. The second sample is only strengthened at the positive moment zone. The ultimate load raised by $143.23 \%$ in comparison to the as seen in Fig. 28. When using the strengthening bar in only the positive moment zone led to increase on ultimate load about $16.67 \%$ relative to the case when the strengthening bars is put in only the negative moment region. Therefore, it can be concluded that when adopting a high strengthening ratio, strengthening only the negative moment region is better than strengthening only the positive moment region. A reverse action was obtained in case of adopting a small strengthening ratio. This is maybe attributed to that when adopting a high quantity of strengthening the probability of the formation of plastic hinges in the negative moment region may increase. So, the redistribution of loading will occur. This is due to higher capacity which increases the corresponding failure load. Therefore, strengthening the negative moment region gave better performance. On another side, when using small strengthen quantity causes a reduction in the slab capacity. This resulted in reducing the probability of the formation of the plastic hinge. So, the importance of strengthening the negative moment region may decrease, and strengthening the positive moment region will be better.

Effect of changing the strengthening location when adopting $100 \mathrm{~mm}$ NSM reinforcement spacing on the load-deflection curves is shown in Fig. 29, linear and nonlinear behavior is also recorded in these specimens. After that, the plastic hinges occurred approximately at the load $175 \mathrm{KN}$ when using the strengthening bars just in the negative moment zone. Then, the slab failed gradually and showed higher ductility before failure. 


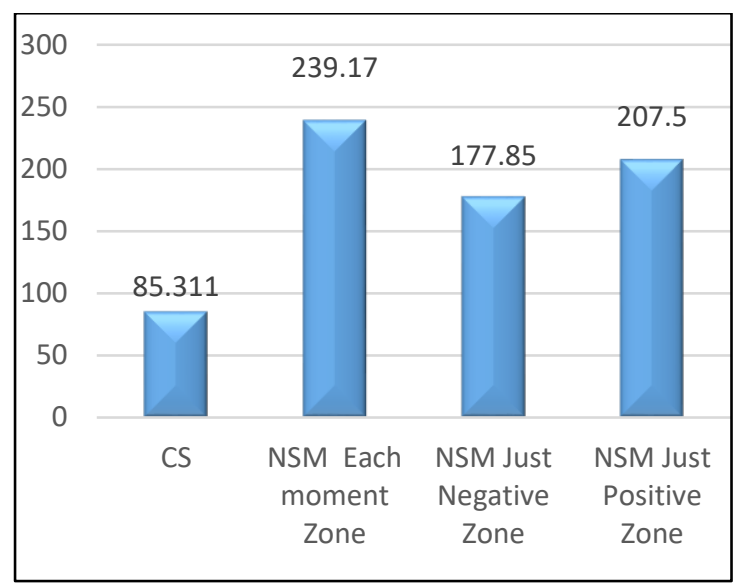

Fig. 28. Influence of NSM location at $100 \mathrm{~mm}$ on ultimate load.

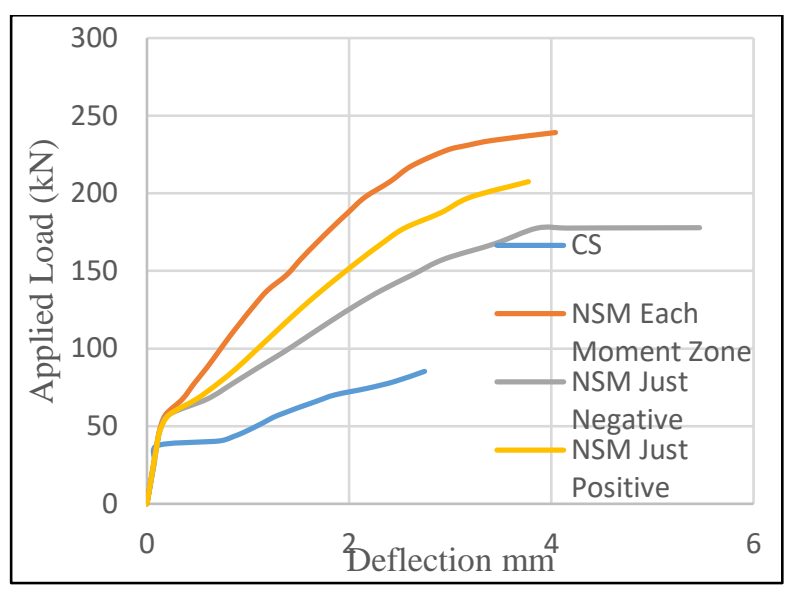

Fig. 29. Load-deflection curves of both moment zones, just negative moment zone and positive moment.

\subsection{Bar Diameter of NSM.}

\subsubsection{Effect of bar diameter when using 70mm NSM bars spacing}

The effect of NSM diameter bar is presented in Fig. 30. For slab SS96.9 steel bars having diameter of $10 \mathrm{~mm}$ have been used as NSM reinforcement. This Specimen illustrated an increase in the load capacity of about $9.92 \%$ compared to those strengthened by $8 \mathrm{~mm}$ bar diameter. While using of $12 \mathrm{~mm}$ bar diameter gave an enhancement of about $3.74 \%$ more than specimen SS96.9 which strengthened by $10 \mathrm{~mm}$ in diameter.

Fig. 31 illustrates effect of changing the bar diameter of NSM strengthening bars on the loaddeflection curves. It can be seen that the stiffness considerably effected by changing bars diameter of strengthening bars beyond cracking stage. It can also be observed that when using $12 \mathrm{~mm}$ bars diameter as NSM bars gave an enhancement of deflection about $6.73 \%$ higher than those contain $10 \mathrm{~mm}$ bars diameter and about $6.45 \%$ when using $8 \mathrm{~mm}$ in diameter.

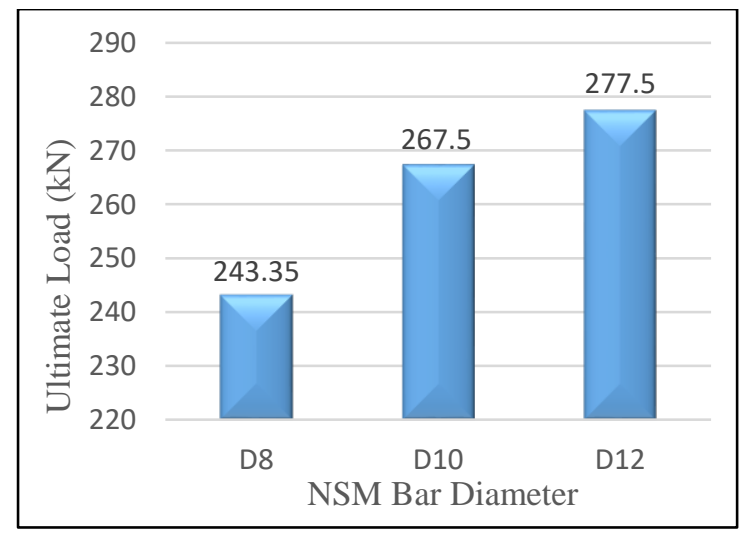

Fig. 30. Influence bar diameter of NSM at $70 \mathrm{~mm}$ on ultimate load.

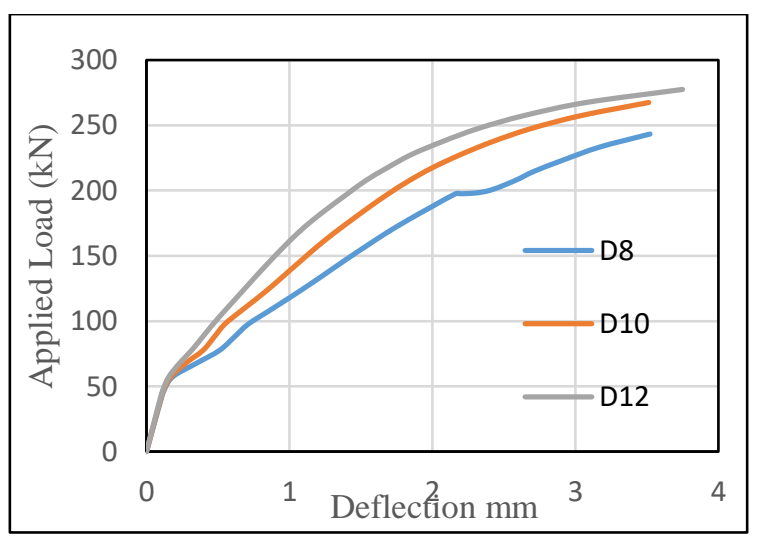

Fig. 31. Load-deflection curves of changing bar diameter of NSM. 


\subsubsection{Effect of bar diameter when using 100mm NSM bars spacing}

Specimen SS94.9 showed an increase in load capacity of about $20.23 \%$ when steel bars diameter is changed from $8 \mathrm{~mm}$ to $10 \mathrm{~mm}$. While increasing bars diameter from $10 \mathrm{~mm}$ to $12 \mathrm{~mm}$ gave a decrease of about $8.15 \%$. This may because that when using a greater diameter, steel bars will apply higher stresses on the concrete cover then those of a smaller diameter, thus causing a decrease in the slab capacity. The effect of NSM diameter bar is presented in Fig. 32.

Effect of changing strengthening bars diameter on the load-deflection curves is illustrated in Fig. 33. It is appearing that the deflection has the same path with load at the linear stage. Plastic hinge formed at the load (190, 230 and 220) KN when using the (8, 10 and 12) NSM bars diameter and after that, the slab failed gradually and showed more ductility before failure. Also it is shown that higher stiffness when using $12 \mathrm{~mm}$ bar diameter NSM at positive and negative moment zone, while smaller stiffness is obtained when the bar diameter became10mm or $8 \mathrm{~mm}$.

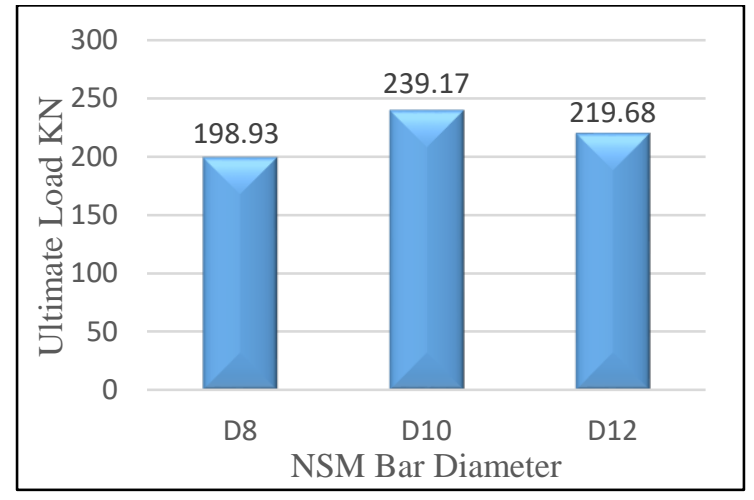

Fig. 32. Influence bar diameter of NSM at $100 \mathrm{~mm}$ on ultimate load.

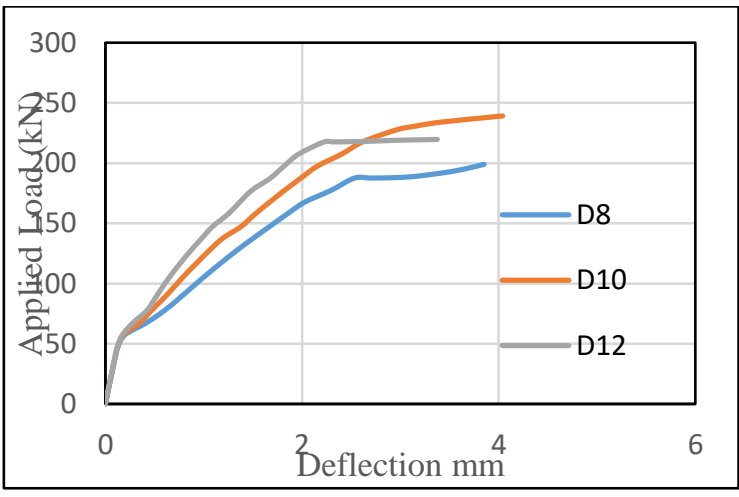

Fig. 33. Load-deflection curves of changing bar diameter of NSM.

\section{CONCLUSION}

Nonlinear finite element analysis with aid of the ANSYS program of continuous one-way slab RC slab strengthened by the NSM technique was presented in this study. The finite element simulations were verified with the experimental tests. Number of parameters that may affect the performance of strengthened continuous slabs were also investigated. Based on the obtained results the following conclusions are drawn:

1. The 3D Finite Element model used in this study is capable of simulating the behavior of continuous one-way RC slabs strengthened by NSM bars under static loads with an error that did not exceed $6.64 \%$. The expected crack profiles and ultimate loads are similar to the findings of the studies. 
2. The compressive strength of concrete has a considerable effect on the ultimate load of continuous slab although it strengthened with high ratio of NSM steel bar. Therefore, increasing it twice gave an increasing in ultimate load to about $58 \%$.

3. When NSM bars spaced $70 \mathrm{~mm}$ on centers located only in the negative moment zone; the increasing of about $135.5 \%$ compared with the CS was obtained. Whereas using the same strengthening amount in positive moment zone only yielded an increasing in the ultimate load by $108 \%$ relative to the CS.

4. When using a high strengthening ratio, strengthening only the negative moment region is better than strengthening only the positive moment region. A reverse action was obtained in case of using a small strengthening ratio.

5. Changing of the diameter of NSM bars from $8 \mathrm{~mm}$ to $10 \mathrm{~mm}$ led to increase in the load capacity by about $9.92 \%$ and $20.23 \%$ when number of strengthening bars are 6 and 4 respectively. While using NSM bar diameter of $12 \mathrm{~mm}$ instead of $10 \mathrm{~mm}$ gave an enhancement of about $3.74 \%$ and $8.15 \%$ when number of strengthening bars are 6 and 4 respectively.

\section{REFERENCES}

ANSYS - release version 19, “A Finite Element Computer Software Theory and User Manual for Nonlinear Structural Analysis", ANSYS 2019, Inc. Canonsburg, PA.

Parretti, R. and Nanni, A. (2004), "Strengthening of RC Members Using Near-Surface Mounted FRP Composites: Design Overview”, Advances in Structural Engineering Vol. 7 No. 5 .PP. 1-16.

Augustine, F. W., (2013), "Strengthening rectangular beams with NSM steel bars and externally bonded GFRP”. M. Sc. thesis, Dept. of Civil Engineering, College of Engineering, Kansas State Univ.

Ashteyat, A. M, Al Rjoub, Y. S., Obaidat, A. T. and Dagamseh, H., (2019) "Strengthening and repair of one-way and two-way self-compacted concrete slabs using nearsurface-mounted carbon-fiber-reinforced polymers", Volume: 22 issue: 11, pp. 2435-2448.

Abdallah M., Al Mahmoud, F., Khelil, A., Mercier, J. and Almassr, B., (2020), “Assessment of the flexural behavior of continuous RC beams strengthened with NSM-FRP bars, experimental and analytical study", Composite Structures, Vol. 242. 
Shakir, Q.M. and Kamonna, H.H., (2018), "The Behavior of High Strength Self-Compacting Reinforced Concrete Corbels Strengthened with NSM Steel Bars”. International Journal on Advanced Science Engineering Information Technology. Vol.8. No. 4. pp. 1022-1028.

Thamrin, R. Haris, S and Zaidir, (2019), "Shear strengthening of reinforced concrete beams with near surface mounted steel bars". M ATEC. pp. 1-6.

Askandar, N.H. and Mahmood, A.D., (2020), “Torsional Strengthening of RC Beams with Near-Surface Mounted Steel Bars". Advances in Materials Science and Engineering Vol. 2020, Article ID 1492980. pp. 1-11. https://doi.org/10.1155/2020/1492980.

Abdzaid, H.M. and Kamonna, H.H., (2019), "Flexural strengthening of continuous reinforced concrete beams with near-surface-mounted reinforcement", Practice Periodical on Structural Design and Construction (C) ASCE, Vol.24. No.3 PP.1-10 DOI: 10.1061/(ASCE)SC.19435576.0000428 .

Kammona, H.H. and Al-Issawi, A.S.H., (2018), "Estimation of Maximum Shear Capacity of RC Deep Beams Strengthened by NSM Steel Bars”. Journal of University of Babylon, Engineering Sciences, Vol. 26. No.3. pp. 13-22.

Al-Issawi, A. S. H. Kamonna and H. H., (2020), "Experimental study of RC deep beams strengthened by NSM steel bars”, Materials Today: Proceedings, Vol. 20, Part 4, pp. 540-547. Willam, K. J. and Warnke, E. P., (1974), "Constitutive Model for Triaxial Behaviour of Concrete, Seminar on Concrete Structures Subject to Triaxial Stresses", International Association of Bridge and Structural Engineering Conference, Bergamo, Italy, pp. 174.

ANSYS, 2016, ANSYS Release 17.0, "Finite Element Analysis System", SAS IP, Inc.

Hassoun, M. N. and Al-Manaseer, A., 2015, "Structural Concrete Theory and Design”, Sixth Edition, John Wiley \& Sons, Inc., Hoboken, New Jersey. 